\title{
Empirical methods for the estimation of debris flow deposition areas
}

\author{
C. Achille ${ }^{1}$, D. De Wrachien ${ }^{2}$, F. Fassi ${ }^{1} \&$ S. Mambretti ${ }^{3}$ \\ ${ }^{I}$ Dept. BEST, Politecnico di Milano, Italy \\ ${ }^{2}$ Dept. of Agricultural Engineering, State University of Milan, Italy \\ ${ }^{3}$ DIIAR, Politecnico di Milano, Italy
}

\begin{abstract}
Debris and hyper-concentrated flows are among the most destructive of all water-related disasters and in recent years have attracted more and more attention from the scientific and professional communities and concern from public awareness, due to the increasing frequency with which they occur and the death toll they claim. The study of debris flows can be subdivided into three main topics: assessment of the magnitude of the phenomenon; study of debris flow motion; determination of the extension of the deposits.

This last issue is of paramount importance from an engineering point of view, due to the fact that it determinates which areas must be considered at risk, with all the consequences linked to the protection of population, and the predisposition of safety plans concerning different activities such as building construction.

In this paper, a review of the most important empirical procedures of prediction of depositional areas is presented, with the aim to verify the applicability of the formulas to events different from those for which the methods were calibrated, and then to try to unify them, in order to originate a more reliable methodology.

Laboratory tests were carried out to integrate the data available in literature. The experimental data have been recorded with photogrammetry methods and 3D models of the deposits have been designed and validated.

The proposed empirical method will allow us to improve both mitigation measures and hazard mapping procedures.

Keywords: debris flow, empirical method, deposits on alluvial fan, laboratory tests.
\end{abstract}




\section{Introduction}

Debris flows are among the most destructive of all water-related disasters. Therefore, accurate prediction of their run-out distances, magnitudes and velocities plays a role of paramount importance for planning and designing appropriate structural and non-structural defence measures.

The study of debris flows can be subdivided into three main problems, which usually are studied separately by researchers: triggering, propagation and deposition [1].

In this paper, deposition phenomena have been studied in order to compute the extension of the deposits over the depositional area, the alluvial fans, the function of different characteristics of the fan and of the debris flow. The importance of the problem is related to the assessment of the area to be considered at risk, with all the consequences tied to the protection of population and the predisposition of safety plans or restrictions of possible activities or buildings $[2,3]$.

Therefore, it is necessary to have methods which allow a reliable prediction of the debris flow hazardous areas; to this end, many empirical methods have been developed, based on data of real events and on experimental tests carried out in laboratories, as will be shown in this paper.

At a first glance, empirical methods seem to be more inaccurate than physically based, but so far many uncertainties are still related with the estimation of the parameters describing the rheology of debris flow [4-6]: the estimation of debris flow depositional areas by physically based models is not less uncertain than that done by simpler empirical methods.

In this paper, a number of empirical methods are presented, and their applicability is tested to events different from those used for their calibration, in terms of magnitude and material. The errors in the estimation of inundated areas and run-out lengths obtained through the empirical methods were calculated, comparing the actual areas and lengths with those predicted, in order to assess their reliability. Moreover, laboratory tests have been performed and a new formula has been developed.

\section{Empirical methods}

Empirical methods can be divided into two broad classes. The first consists of the methods based on the regression of experimental [7] or field data [8-12] the latter category is related to the methods based on some physical (usually simplified) considerations about the motion of the debris flow, introducing the idea of gravitational and kinetic energy, which leads to the definition of the socalled 'energy line' [13-15].

Obviously, one parameter to be input in all these model is the event magnitude $V$, which is the volume involved in the event, tied to the return period, and which is one of the main parameters influencing the extension of deposits. This magnitude is uncertain and the methods to evaluate it may lead to very 
sparse results [16]; for consistency, in this paper the event magnitude is supposed to be known and the same value has been used for the different methods.

The main problem with empirical methods is that each of them was calibrated and tested with reference to specific ranges of volumes and to a specific kind of material. For example, granular debris flows have a very different behaviour from volcanic debris flows; some methods were obtained on the basis of a large range of volumes, such as the methods of Iverson and Corominas, while others were calibrated for a very specific sample of events, such as Sarno [15] or Taiwan events [8], and therefore they give reasonable results only for catchments very similar to those for which they were purposely calibrated.

\section{Laboratory tests}

Tests have been carried out in the Hydraulic Laboratory of the Politecnico of Milan in order to evaluate the influence of different physical parameters on the extension of fan deposits. A saturated granular material with average diameter $D_{50}=0.005 \mathrm{~m}\left(D_{60} / D_{10}=2.15\right)$, density $\rho_{\mathrm{s}}=2660 \mathrm{~kg} / \mathrm{m}^{3}$ and porosity 0.4 has been used. Experiments have been performed in a channel with a smooth plastic bottom, using three different bulk volumes $V\left(0.002,0.004\right.$ and $\left.0.006 \mathrm{~m}^{3}\right)$. Therefore, considering the density of the solid material and its porosity, the weight of the gravel used in each test was equal to $3.19,6.38$ and $9.58 \mathrm{~kg}$, respectively.

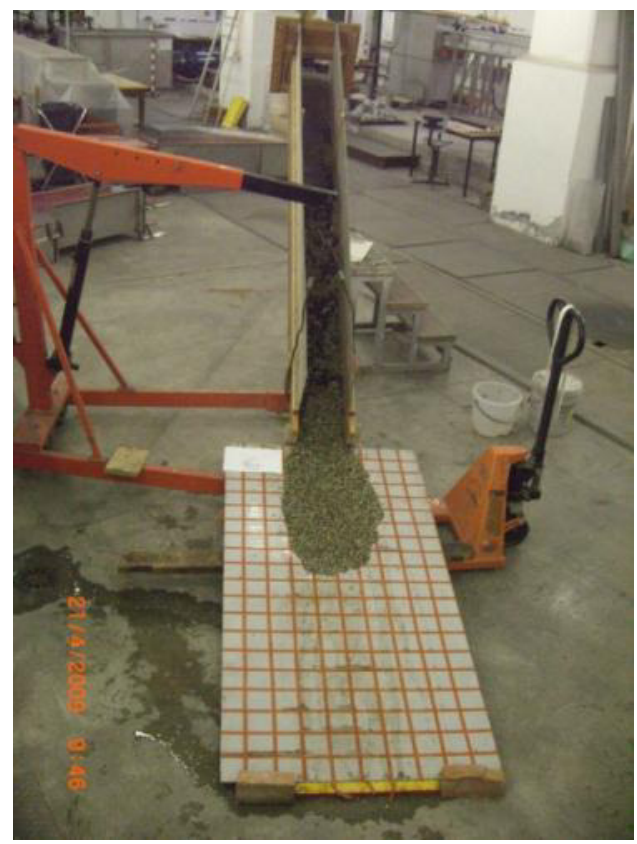

Figure 1: $\quad$ Experimental set-up. 
The experimental set-up is shown in figure 1 . The channel has an adjustable slope $\left(20^{\circ}, 25^{\circ}, 30^{\circ}\right)$, a length equal to $3.10 \mathrm{~m}$ and a rectangular cross-section $(0.5 \mathrm{~m} \times 0.26 \mathrm{~m})$; a removable gate was placed in two different positions, at heights of $1 \mathrm{~m}$ and $2 \mathrm{~m}$ over the fan; the gate represented the origin of the debris flow. At the end of the channel, a metal plane was positioned, representing the alluvial fan; the plane had an adjustable slope $\left(5^{\circ}-10^{\circ}-15^{\circ}\right)$ and was divided into a grid of squares $10 \mathrm{~cm} \times 10 \mathrm{~cm}$; experiments were carried out first on a smooth plane (Manning roughness $\mathrm{n}=0.013 \mathrm{~s} \mathrm{~m}^{-1 / 3}$ ). Then a rough fan was constructed by gluing plastic material (obtaining approximately $\mathrm{n}=0.022 \mathrm{~s} \mathrm{~m}^{-1 / 3}$ ) or by using the same gravel used for the flow (obtaining approximately $\mathrm{n}=0.029 \mathrm{~s} \mathrm{~m}^{-1 / 3}$ ).

Table 1: Experimental test characteristics and results.

\begin{tabular}{|c|c|c|c|c|c|c|c|}
\hline & Roughness & $\begin{array}{c}\text { Slope of } \\
\text { the } \\
\text { channel } \\
\left.{ }^{\circ}\right]\end{array}$ & $\begin{array}{c}\text { Slope of } \\
\text { the fan } \\
{\left[^{\circ}\right]}\end{array}$ & $\begin{array}{c}\text { Volume } \\
\text { V } \\
{[1]}\end{array}$ & $\begin{array}{c}\text { Drop } \\
\text { height } \\
\mathrm{H} \\
{[\mathrm{m}]}\end{array}$ & $\begin{array}{c}\text { Inundated } \\
\text { area } A \\
{\left[\mathrm{~m}^{2}\right]}\end{array}$ & $\begin{array}{c}\text { Run-out } \\
\text { length L } \\
{[\mathrm{m}]}\end{array}$ \\
\hline 1 & \multirow{12}{*}{ Smooth } & \multirow{27}{*}{$30^{\circ}$} & \multirow{4}{*}{$5^{\circ}$} & 2 & \multirow{3}{*}{2} & 0.145 & 0.62 \\
\hline 2 & & & & 4 & & 0.363 & 1.04 \\
\hline 3 & & & & 6 & & 0.530 & 1.19 \\
\hline 4 & & & & 4 & 1 & 0.160 & 0.58 \\
\hline 5 & & & \multirow{4}{*}{$10^{\circ}$} & 2 & \multirow{3}{*}{2} & 0.295 & 0.85 \\
\hline 6 & & & & 4 & & 0.470 & 1.03 \\
\hline 7 & & & & 6 & & 0.255 & 0.95 \\
\hline 8 & & & & 4 & 1 & 0.470 & 1.39 \\
\hline 9 & & & \multirow{4}{*}{$15^{\circ}$} & 2 & \multirow{3}{*}{2} & 0.810 & 2.00 \\
\hline 10 & & & & 4 & & 0.094 & 0.41 \\
\hline 11 & & & & 6 & & 0.218 & 0.62 \\
\hline 12 & & & & 4 & 1 & 0.302 & 0.82 \\
\hline 13 & \multirow{12}{*}{$\begin{array}{l}\text { Rough } \\
\text { (plastic) }\end{array}$} & & \multirow{4}{*}{$5^{\circ}$} & 2 & \multirow{3}{*}{2} & 0.063 & 0.28 \\
\hline 14 & & & & 4 & & 0.142 & 0.45 \\
\hline 15 & & & & 6 & & 0.217 & 0.57 \\
\hline 16 & & & & 4 & 1 & 0.065 & 0.28 \\
\hline 17 & & & \multirow{4}{*}{$10^{\circ}$} & 2 & \multirow{3}{*}{2} & 0.161 & 0.49 \\
\hline 18 & & & & 4 & & 0.196 & 0.54 \\
\hline 19 & & & & 6 & & 0.340 & 0.86 \\
\hline 20 & & & & 4 & 1 & 0.440 & 1.13 \\
\hline 21 & & & \multirow{4}{*}{$15^{\circ}$} & 2 & \multirow{3}{*}{2} & 0.550 & 1.40 \\
\hline 22 & & & & 4 & & 0.159 & 0.44 \\
\hline 23 & & & & 6 & & 0.190 & 0.54 \\
\hline 24 & & & & 4 & 1 & 0.251 & 0.70 \\
\hline 25 & \multirow{3}{*}{$\begin{array}{l}\text { Rough } \\
\text { (gravel) }\end{array}$} & & $5^{\circ}$ & 2 & \multirow{3}{*}{2} & 0.069 & 0.26 \\
\hline 26 & & & $10^{\circ}$ & 2 & & 0.081 & 0.33 \\
\hline 27 & & & $15^{\circ}$ & 2 & & 0.106 & 0.40 \\
\hline 28 & \multirow{3}{*}{$\begin{array}{l}\text { Rough } \\
\text { (plastic) }\end{array}$} & $15^{\circ}$ & \multirow{3}{*}{$10^{\circ}$} & 4 & \multirow{3}{*}{2} & 0.127 & 0.38 \\
\hline 29 & & $20^{\circ}$ & & 4 & & 0.152 & 0.48 \\
\hline 30 & & $25^{\circ}$ & & 4 & & 0.145 & 0.62 \\
\hline
\end{tabular}


A total number of 30 experiments were performed, with different combinations of the parameters: debris flow magnitude, height of falling, channel slope, fan slope, fan roughness. For each test, the following quantities were measured: maximum deposit length and width, thickness at the apex, at the centre and at the toe of the deposit, deposit area, deposit volume (which is the volume actually reaching the fan, while a part of the volume, generally small, remains on the bottom of the channel).

These test characteristics have been summarized in table 1 .

\section{Data elaboration}

In order to carry out, quickly and accurately, the required parameters, two photogrammetric approaches were followed. The former is the rigorous classical methods called "image rectification" that allows accurate 2D measurements in the XY plane and consequently, in this case, was used to compute the length and the width of the deposit during the flow. To do it, it is necessary to tape the simulated flow using an HD calibrated camera and then to extract some image frames of the video at the time spots of interest; afterwards the photogrammetric transformation is applied on the single extracted frames. In order to get 2D accurate measurements from the images two step were followed: i) the elimination of the distortions caused by the camera lenses applying back to the image the camera inner calibration parameters and ii) the transformation of the perspective projection typical of the camera in orthographic projection using a method called image rectification. Both analytical and geometrical methods are tested.
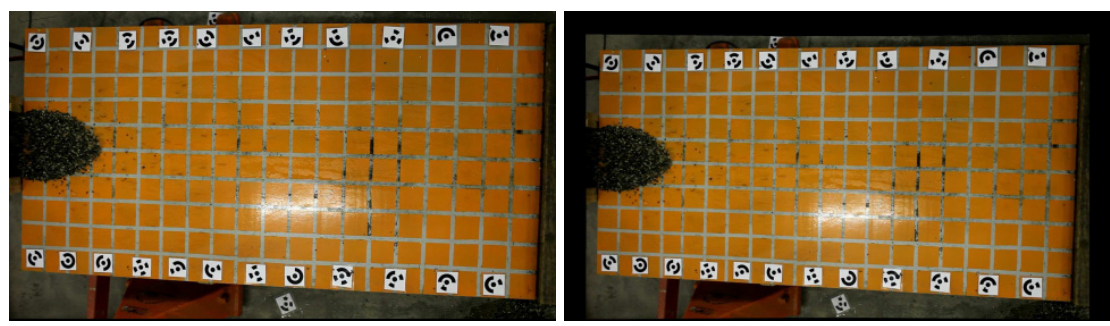

Figure 2: Original frame (left) and the same corrected from image distortion (right).

The camera used in the laboratory was a Canon 5D Mark II with a 35mm fix lens pre-calibrated on site. The camera was placed over the plane at a high of approximately $3.3 \mathrm{~m}$ in order to get an image resolution of about $0.5 \mathrm{~mm}$ on the ground. That can provide a final pixel size on the rectified image of about $2 \mathrm{~mm}$.

Parameters to be measured were the thickness at the apex, at the centre and at the toe of the deposit, the deposit area and its volume. These are typically threedimensional measurements that need a 3D reconstruction of the deposit. The 3D model is created using the latter mentioned photogrammetric method, the socalled "image matching" that allows us to build 3D points models of the inquired 


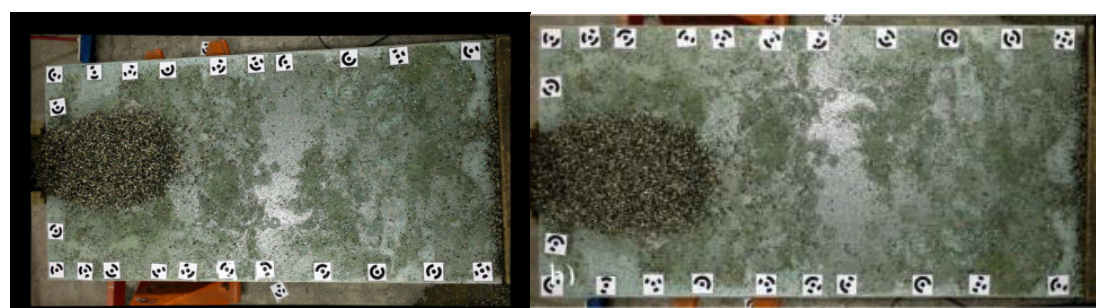

Figure 3: On the left an undistorted video frame with a ground resolution of $0.6 \mathrm{~mm}$ and on the right the corresponding rectified images with a ground resolution of $1.8 \mathrm{~mm}$.

object from a series of images of the same scene taken from different positions around it. The procedure has been completely computerized.

At least 15 images have to be collected, and to this end a so-called multiimage acquisition set around the object was used. That means a number of photos of the same object were taken, each of them with a different capture angle but with a very short distance between adjacent captures. Automatic procedures of image orientation were used to calculate automatically the cameras positions and external orientations; then image matching procedures were used to extract a raw 3D point cloud of the captured scene. The achieved point models had approximately a resolution of about $2 \mathrm{~cm}$. Actually, this is not a very high resolution, but this quite poor result is mainly due to the choice to speed up the elaboration using low-middle resolution images in the process. In fact, these types of elaborations are completely automatic but can be very time consuming: the elaboration time grows exponentially with the resolution of the image.

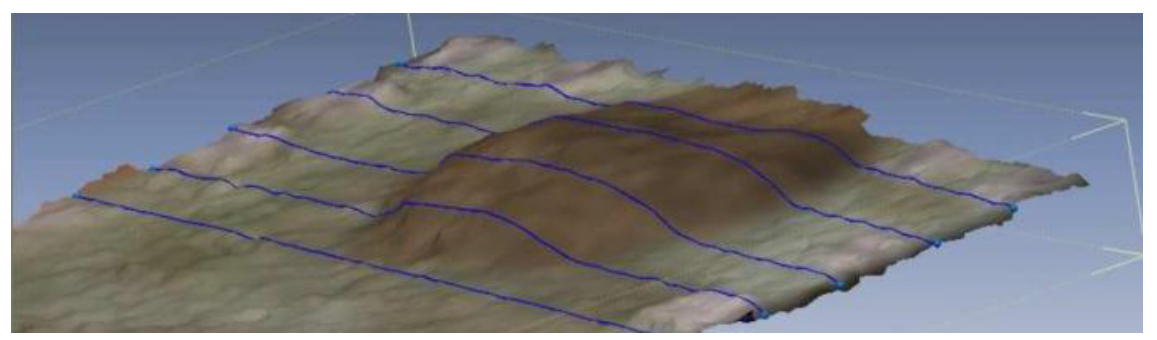

Figure 4: The 3D DSM with the automatic contours extraction of the deposit.

Moreover, the presence of water on the surface brings errors in the automatic procedure of point matching with consequent decrease of resolution. The presence of false corresponding point among images should be eliminated in the final 3D model with a consequent loss of detail. Some post-processes are then necessary to clean the point cloud and to create the final DSM to be used to extract, automatically or manually, the required $3 \mathrm{D}$ information as $3 \mathrm{D}$ coordinates, contours areas and volumes. 


\section{Evaluation of the applicability of empirical methods to experimental data}

In order to evaluate the applicability of empirical methods to the laboratory results, the experimental data have been scaled in order to fall into the range of applicability of the different methods, that is to say in the range of debris flow volumes for which the formulation had been calibrated. This range, with the related scale factor $\lambda$ is reported in table 2 . Since only geometric values (lengths, areas and volumes) are involved in the calculations, a simple geometrical scaling was applied, multiplying the volume of the laboratory test by $\lambda^{3}$. As can be seen, since Liu's data were carried out in laboratory, no scale factor was needed.

Table 2: $\quad$ Range of validity of empirical methods and scale factor $\lambda$ applied to the laboratory data.

\begin{tabular}{|c|c|c|}
\hline Method & Range $\left[\mathrm{m}^{3}\right]$ & $\lambda$ \\
\hline Yu et al. & $10^{4}-10^{5}$ & 250 \\
\hline Berti and Simoni & $10^{4}-10^{9}$ & 1000 \\
Liu & $10^{-3}-10^{-2}$ & 1 \\
Rickenmann & $10^{3}-10^{7}$ & 100 \\
Schilling and Iverson & $10^{4}-10^{9}$ & 1000 \\
Prochaska et al. & $10^{3}-10^{4}$ & 100 \\
Iverson & $10^{4}-10^{9}$ & 1000 \\
Corominas & $10^{4}-10^{9}$ & 250 \\
\hline Toyos et al. & $10^{4}-10^{5}$ & 250 \\
\hline
\end{tabular}

Moreover it has to be underlined that, when the scale coefficient had to be set equal to 1000 , the actual meaning of the carried out results is very low, because if we apply the geometrical scale factor to the single solid grains, the average dimension of the solid material would be approximately equal to $5 \mathrm{~m}$, which is neither realistic nor common.

As a measure of the error carried out when the existing methods are applied to the experimental data collected in laboratory, the ratio $F s$ between the area $A_{\text {calculated }}$ (or the length $L_{\text {calculated }}$ ) obtained by the empirical method and the measured area $A_{\text {actual }}$ (or length $L_{\text {actual }}$ ) was calculated for every laboratory test carried out in the Laboratory:

$$
\begin{gathered}
F S_{A}=\frac{A_{\text {calculated }}}{A_{\text {actual }}}, \\
F S_{L}=\frac{L_{\text {calculated }}}{L_{\text {actual }}} .
\end{gathered}
$$

In table 3, the minimum, maximum and average values obtained for each method are shown. When the ratio is smaller than 1, the method underestimates 
the actual deposit extension; otherwise, the method overestimates the debris flow extension. Hence the ratio can be considered as a 'safety factor', in the sense that it represents a factor for which it is necessary to divide the area/length calculated by the formula in the way to obtain the real extension of debris flow deposit.

Table 3: $\quad$ Values of the ratio $F s$ for area and length obtained from laboratory tests.

\begin{tabular}{|c|c|c|c|c|c|c|c|}
\hline \multirow{2}{*}{ METHODS } & \multicolumn{5}{|c|}{$F s_{A}$} & \multicolumn{3}{c|}{$F s_{L}$} \\
\cline { 2 - 8 } & min. & aver. & max. & min. & aver. & max. \\
\hline $\begin{array}{c}\text { BASED ON REGRESSION OF } \\
\text { DATA }\end{array}$ & \multicolumn{5}{|c|}{} & \multicolumn{3}{c|}{} \\
\hline Yu et al. & 1.05 & 2.86 & 4.73 & 1.08 & 2.55 & 4.02 \\
\hline Berti and Simoni & 0.62 & 1.69 & 2.79 & - & - & - \\
\hline Liu & 1.30 & 4.81 & 11.30 & 1.27 & 3.70 & 6.84 \\
\hline Rickenmann & - & - & - & 1.29 & 3.52 & 5.98 \\
\hline $\begin{array}{c}\text { Schilling and Iverson } \\
\text { Prokaska et al. }\end{array}$ & 7.32 & 19.85 & 32.82 & - & - & - \\
\hline $\begin{array}{c}\text { New regression line proposed } \\
\text { by the authors in this paper }\end{array}$ & $\mathbf{0 . 4 6}$ & - & - & 0.25 & 0.84 & 1.67 \\
\hline ENERGY LINE BASED & & 1.21 & $\mathbf{1 . 9 3}$ & $\mathbf{0 . 4 7}$ & $\mathbf{1 . 1 9}$ & $\mathbf{1 . 8 8}$ \\
\hline Iverson & & & & 4.01 & 5.93 & 7.48 \\
\hline Corominas & & & & 1.19 & 1.85 & 2.81 \\
\hline \begin{tabular}{c} 
Toyos et al. \\
\hline
\end{tabular} & & & & 2.56 & 3.99 & 6.32 \\
\hline
\end{tabular}

As can be seen, the obtained $F s$ values are very scattered and some of the carried out results are far from acceptable.

In particular, Shilling and Iverson's method leads to an estimation of the deposit area up to 30 times higher of the actual one. This is due to the fact that this method is not really applicable to laboratory data, since it was developed for volcanic debris flow (lahars) with rheological characteristics very different from those of the granular material we used.

On the other hand, the method of Prokaska et al. [12] gives, on average, an underestimation of the run-out length, but this method, too, was calibrated for a very specific kind of debris flow, happening on recently burned grounds.

The other methods give in general an overestimation of the inundated area and of the run-out length, so, if they were applied for the delimitation of an area potentially at risk of debris flow, they would be on the safe side. The problem is that their predictions are too uncertain, since they could overestimate, on average, the debris flow extension by up to 6 times the real extension.

Through the interpolation of all available data collected from the literature volumes, run-out lengths and/or depositional areas of real debris flow events as in [7-12] - and from the laboratory tests performed in our laboratory, new global 
formulas for the evaluation of depositional areas and run-out lengths on the alluvial fan as functions of the debris flow magnitude have been developed, with the aim to achieve a formulation giving acceptable results for a very wide range of volumes and materials. The resulting formula fits the data of debris flow both at the laboratory scale and at the field scale, as can be observed in figures 5 and 6.

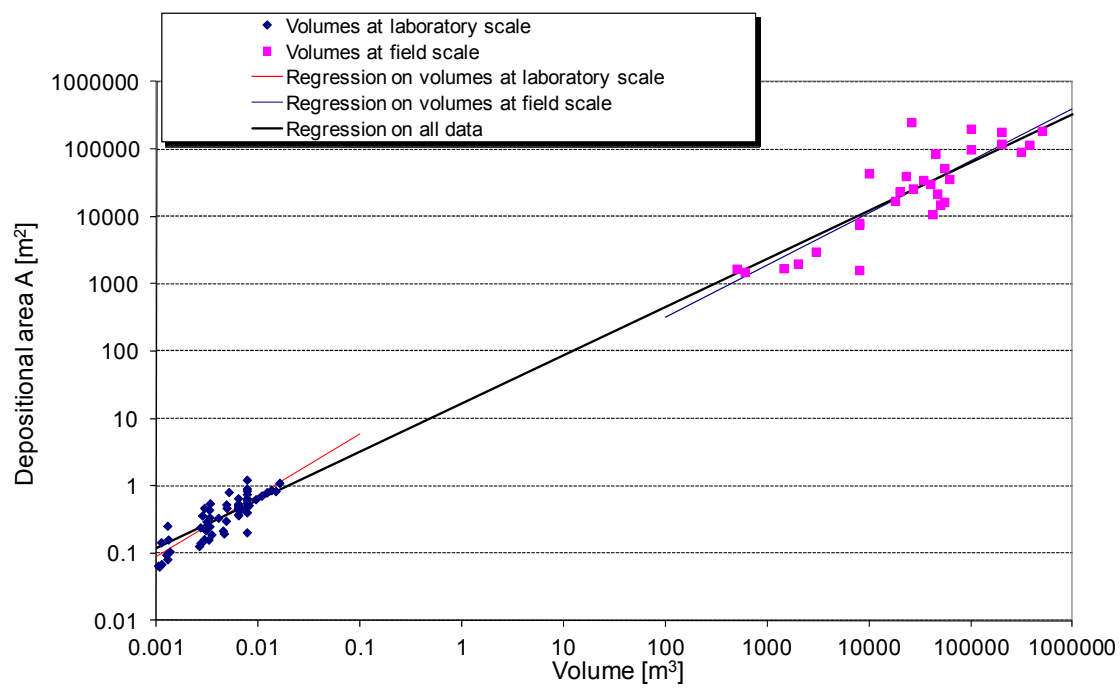

Figure 5: Authors' formula for depositional area estimation.

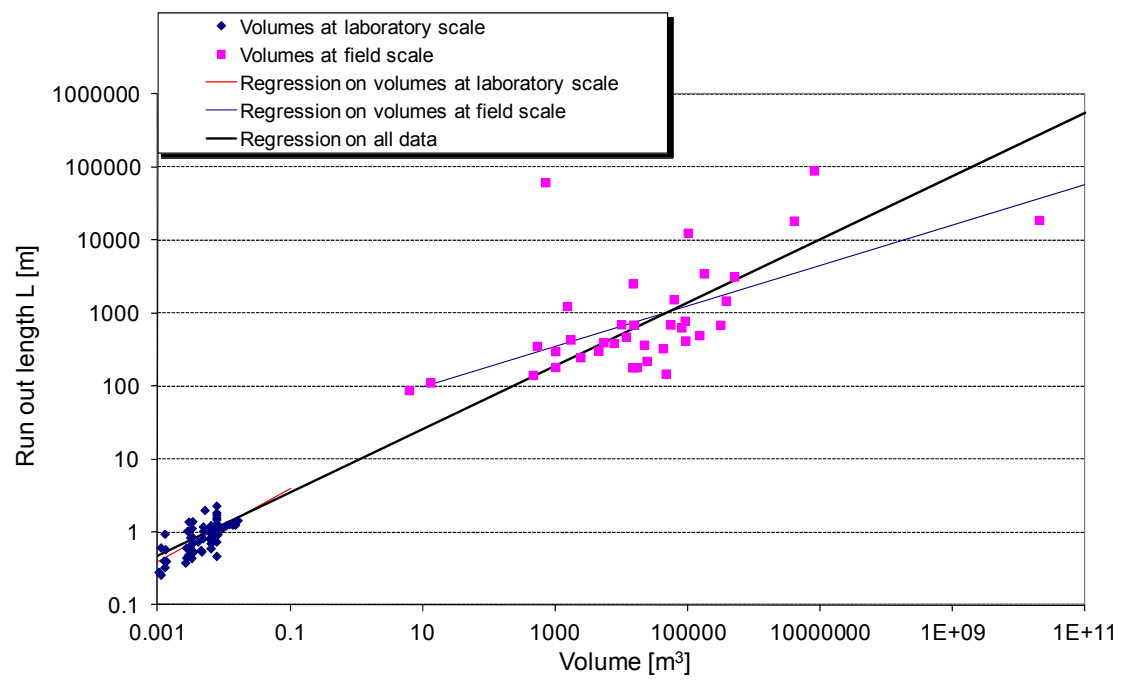

Figure 6: New regression formula for run-out length estimation. 
The formula for the new regression line for depositional area estimation (figure 5), based on all the available experimental data, is:

$$
A=16.5 \cdot V^{0.72}
$$

and the related correlation coefficient is $R^{2}=0.98$.

The formula for the new regression line for depositional length estimation (figure 6), based on all the available experimental data, is:

$$
L=9.34 \cdot V^{0.434}
$$

and the related correlation coefficient is $R^{2}=0.93$.

On average, the new formula, when applied to all the available data, gives an $F_{S_{A}}$ equal to 1.16 for the depositional area, and an $F_{S_{L}}$ equal to 1.4 for the run-out length. The average, maximum and minimum safety factors obtained from the application of the new formula to the available data are shown in table 4 .

Table 4: Average, maximum and minimum safety factor calculated on all the available events, applying the new formulas proposed.

\begin{tabular}{|c|c|c|}
\cline { 2 - 3 } \multicolumn{1}{c|}{} & \multicolumn{2}{c|}{ Granular debris flows } \\
\hline & $F s_{A}$ & $F S_{L}$ \\
\hline min & 0.28 & 0.18 \\
\hline average & 1.12 & 1.31 \\
\hline max & 3.13 & 6.70 \\
\hline
\end{tabular}

So, on average, the results obtained by these formulas are good if compared to the mean Fs obtained by the pre-existing methods presented in table 4 and surely acceptable if used for designing purposes. On the other end, it is to be underlined that the problem is still the high dispersion of data.

\section{Concluding remarks}

This study confirmed that, since the inundated area and the run-out length of a debris flow strongly depend on physical parameters characterizing both the debris flow mixture (water content, density of the material,...) and the environment in which the debris flow develops and deposits (e.g. the alluvial fan roughness), it is very difficult to predict with sufficient reliability the extension of debris flow deposits using empirical formulas because the results are very sparse; therefore these formulas, obtained and calibrated on very specific data sets or experimental catchments, can be used as instruments to estimate depositional areas and run-out lengths for a generic catchment, in the phase of planning or designing only by highly trained technicians or engineers with the help of field analysis.

However, from the application of the empirical methods both to laboratory data, it results that satisfactory results can be obtained with the Authors' formulas for both area and run-out length and with the method of Corominas for the run-out length only. 
This latter method (or family of methods), which is based on physical considerations, although simplified, should be more deeply investigated.

However, developments of this research will be towards the assessment of a model more complex and physically based, able to take into account all the relevant parameters and to produce more reliable results to be used in real planning.

Moreover, photogrammetric measurement techniques have been tested. They proved to be very useful to take quick, cheap but accurate and automatic measurement during laboratory tests. Future developments of the methodology will be the installation of a fixed laboratory photogrammetric set with fixed capture positions and good illumination in order to increase the acquisition quality and the final measurement accuracy. The improvement in the accuracy and speed of the methodologies used to carry out automatic 3D modelling from images are very important in the hydro-geological and environmental field, where these measurements have to be repetitively performed both in laboratory and especially in field, to monitor dangerous mass of sediments.

\section{References}

[1] Lorenzini G, Brebbia C, Emmanouloudis D (eds) (2006) Monitoring, simulation, prevention and remediation of dense and debris flows. Southampton, UK, WIT Press.

[2] Einstein H (1988) Special lecture: Landslide risk assessment procedure. Int. Symposium on Landslides. In: Bonnard C (ed) Landslide, v2, pp 10751090.

[3] Schultz B (2006) Flood management under rapid urbanization and industrialization in flood-prone areas: A need for serious consideration. Irrigation and Drainage 55 suppl 1, 3-8.

[4] Iverson R (2003) The debris-flow rheology myth. In: Rickenmann D, Chen C (eds) Debris-flow hazards mitigation: Mechanics, prediction, and assessment v1, Rotterdam, Millpress, pp 303-314.

[5] Mambretti S, Larcan E, De Wrachien D (2008a) Theoretical and experimental analysis of debris flow: Rheology and two-phase modelling irrigation and drainage, 57(5):555-570.

[6] Mambretti S, Larcan E, De Wrachien D (2008b) 1D modelling of dambreak surges with floating debris. Biosystems Engineering, 100(2):297308.

[7] Liu X (1996) Size of debris flow deposition: Model experiment approach. Environmental Geology 28(2):70-77.

[8] Yu F, Chen C, Chen T, Hung F, Lin S (2006) A GIS process for delimitating areas potentially endangered by debris flow. Natural Hazards 37:169-189.

[9] Berti M, Simoni A (2007) Prediction of debris flow inundation areas using empirical mobility relationships. Geomorphology 90:144-161.

[10] Rickenmann D (1999) Empirical relationships for debris flows. Natural Hazards 19:47-77. 
[11] Iverson R, Schilling S (1997) Automated, reproducible delineation of zones at risk from inundation by large volcanic debris flows Proceedings of first international conference on debris-flow hazards mitigation: Mechanics, prediction and assessment, San Francisco, August 7-9, 1997, ASCE: 176186.

[12] Prochaska A, Santi P, Higgins J, Cannon S (2008) Debris-flow run-out predictions based on the average channel slope (ACS). Engineering Geology 98:29-40.

[13] Iverson R (2003) The debris-flow rheology myth. In: Rickenmann D, Chen C (eds) Debris-flow hazards mitigation: Mechanics, prediction, and assessment v1, Rotterdam, Millpress, pp 303-314.

[14] Corominas J (1996) The angle of reach as a mobility index for small and large landslide. Canadian Geotechnical Journal 33:260-271.

[15] Toyos G, Oramas Dorta D, Oppenheimer C, Pareschi M, Sulpizio R, Zanchetta G (2006) GIS-assisted modelling for debris flow hazard assessment based on the event of May 1998 in the area of Sarno, southern Italy: Part I: Maximum run-out. Earth Surface Processes and Landforms 32: 1491-1502.

[16] Mambretti S (2007) Valutazione della magnitudo di colate detritiche in funzione del tempo di ritorno nel Bacino di Val Gola (BG) GEAM, 1:1524. 